\title{
Technique for myocardial protection in pulmonary atresia intact ventricular septum
}

\author{
Ronald K. Woods, MD, PhD, Milwaukee, Wis
}

\footnotetext{
From the Division of Pediatric Cardiothoracic Surgery, Department of Surgery, Medical College of Wisconsin and Herma Heart Center and Children's Hospital of Wisconsin, Milwaukee, Wis. Disclosures: Author has nothing to disclose with regard to commercial support.

Received for publication Nov 9, 2016; accepted for publication March 26, 2017; available ahead of print April 15, 2017.

Address for reprints: Ronald K. Woods, MD, PhD, Herma Heart Center and Children's Hospital of Wisconsin, 9000 W Wisconsin Ave, Milwaukee, WI 53226 (E-mail: RWoods@chw.org).

J Thorac Cardiovasc Surg 2017;154:e65-6

$0022-5223 / \$ 36.00$

Copyright (c) 2017 by The American Association for Thoracic Surgery

http://dx.doi.org/10.1016/j.jtcvs.2017.03.079
}

How to best protect the myocardium is a challenging situation that arises when a patient with pulmonary atresia intact ventricular septum (PA-IVS) and right ventricular dependent coronary circulation (RVDCC) requires an intracardiac procedure. We describe a simple, effective technique that addresses this problem.

\section{CLINICAL SUMMARY}

A premature (35 weeks) 2.1-kg male neonate with a diagnosis of PA-IVS was successfully resuscitated from cardiac arrest during coronary angiography that demonstrated RVDCC_right ostial atresia, circumflex, and distal left anterior descending coronary artery supplied by the right ventricle. Prior echocardiography had demonstrated multiple sinusoids, tortuous duct, diminutive right ventricle, and a tricuspid valve $z$ score of -4.7 . The patient was managed with prostaglandin E1 and beta blockade and listed status 1A for cardiac transplantation. The absence of a suitable donor organ, progressive desaturation, and acceptable pulmonary vascular resistance led to the decision to proceed to a Glenn procedure at age 3 months. Interval echocardiography demonstrated proximal left pulmonary artery stenosis and right-to-left bowing of the atrial septum with small interatrial communication. On the latter issue, a lengthy multidisciplinary discussion of the various options led to the plan of concomitant surgical septectomy.

\section{SURGICAL TECHNIQUE}

The patient was supported on cardiopulmonary bypass (CPB) with cannulation of the innominate vein, inferior vena cava, and aorta and the duct was closed. As is customary in these circumstances, venous drainage was closely regulated to keep the heart full and ejecting. Using a bifurcated cardioplegia line, preparations were made to simultaneously administer cardioplegia (del Nido) into the aortic root and through the tricuspid valve into the right ventricle (Figure 1). With aortic crossclamp, antegrade cardioplegia was initiated, caval snares secured, and through a

\section{DISCUSSION}

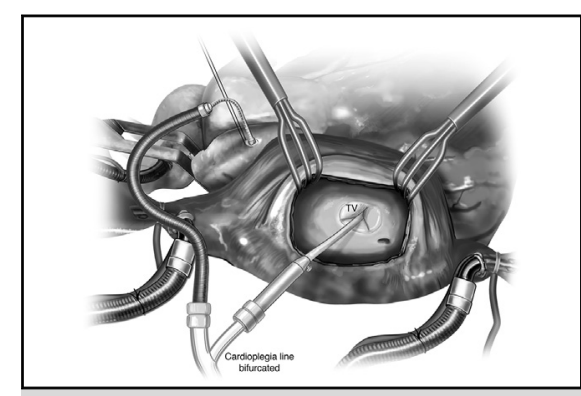

Delivery of cardioplegia into the aorta and right ventricle.

Central Message
For pulmonary atresia intact ventricular
septum, dual aortic root and transtricuspid
valve delivery of cardioplegia into the right
ventricle is a simple, reliable method of
providing myocardial protection.

See Editorial Commentary page e67.

limited right atriotomy a 6 Fr cannula (approximately twice the diameter of the aortic root catheter) connected to the bifurcated line was inserted through the tricuspid valve and maintained in position under direct vision (this was accomplished in $<10$ seconds). With infusion, the tricuspid valve remained competent and a smooth arrest was achieved and all areas of the myocardium appeared well perfused. Septectomy, patch reconstruction of the central and left pulmonary artery, Glenn procedure, and atrial closure were completed in the usual manner. With release of the aortic clamp, the heart promptly resumed sinus rhythm, CPB was managed as previously with no signs of ischemia, and the procedure completed without incident. The patient continues to do well as an outpatient at age 9 months and remains listed as status II.

Despite being a source of much consternation among surgeons, very little has been published on the topic of managing CPB for patients with PA-IVS and RVDCC. The consensus is that the heart should be kept full to avoid decompression of the right ventricle. ${ }^{1-3}$ Anecdotally, this seems to work well for most surgeons and few would be willing to knowingly adopt a decompressive CPB strategy given the potential consequences. To our knowledge, the description by Asou and colleagues ${ }^{1}$ of bicaval drainage 


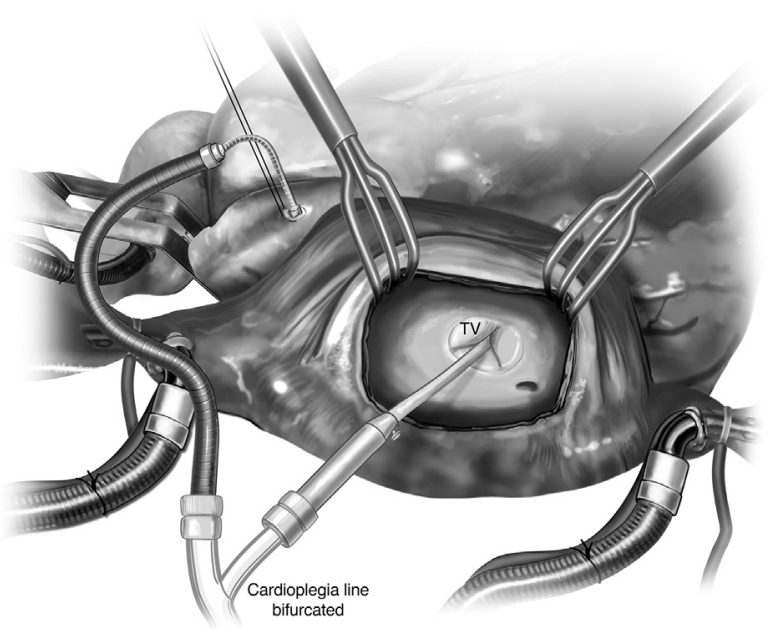

FIGURE 1. Illustration of operative setup and dual administration of cardioplegia into the aortic root and through the tricuspid valve (TV) into the right ventricle.

and atrial infusion of oxygenated blood is perhaps the only report specifically directed at conduct of CPB. This and any other "full right heart" approach is clearly not suitable for an intracardiac procedure. Fortunately, the vast majority of patients can be managed to either cardiac transplantation or Fontan palliation without the need for cardioplegic arrest. In fact, it may be argued that we could have avoided this as well with an earlier catheter-based procedure for the septum. Regardless, the approach we used was easy and seemed to work exceptionally well. This technique presents 2 additional considerations. First, even if cardioplegic arrest is not required for an intracardiac procedure, this approach may be of benefit if ischemia develops on-pump, despite regulation of venous drainage-well administered cardioplegia may be superior to the heart full and beating with ongoing ischemia. Second, although not directly related to the present case, it is our opinion that a successful CPB and cardioplegic strategy for PA-IVS with RVDCC may have implications for hypoplastic left heart syndrome with aortic atresia and mitral stenosis with sinusoids-avoiding an empty left ventricle and dual delivery of cardioplegia into the aorta and the mitral valve may optimize myocardial protection in this potentially at-risk group.

\section{References}

1. Asou T, Matsuzaki K, Matsui K, Karl TR, Mee RBB. Veno-venous bypass to prevent myocardial ischemia during right heart bypass operations in PA, IVS and RV dependent coronary circulation. Ann Thorac Surg. 2000;69:955-6.

2. Susheel Kumar TK, Sinha P, Moulick A, Jonas RA. Risks of extracorporeal membrane oxygenation in patients with coronary anomalies. World J Pediatr Congen Heart Surg. 2010;1:249-53.

3. Guleserian KJ, Armsby LB, Thiagarajan RR, del Nido PJ, Mayer JE. Natural history of pulmonary atresia intact ventricular septum and right-ventricledependent coronary circulation managed by the single-ventricle approach. Ann Thorac Surg. 2006;81:2250-8. 